


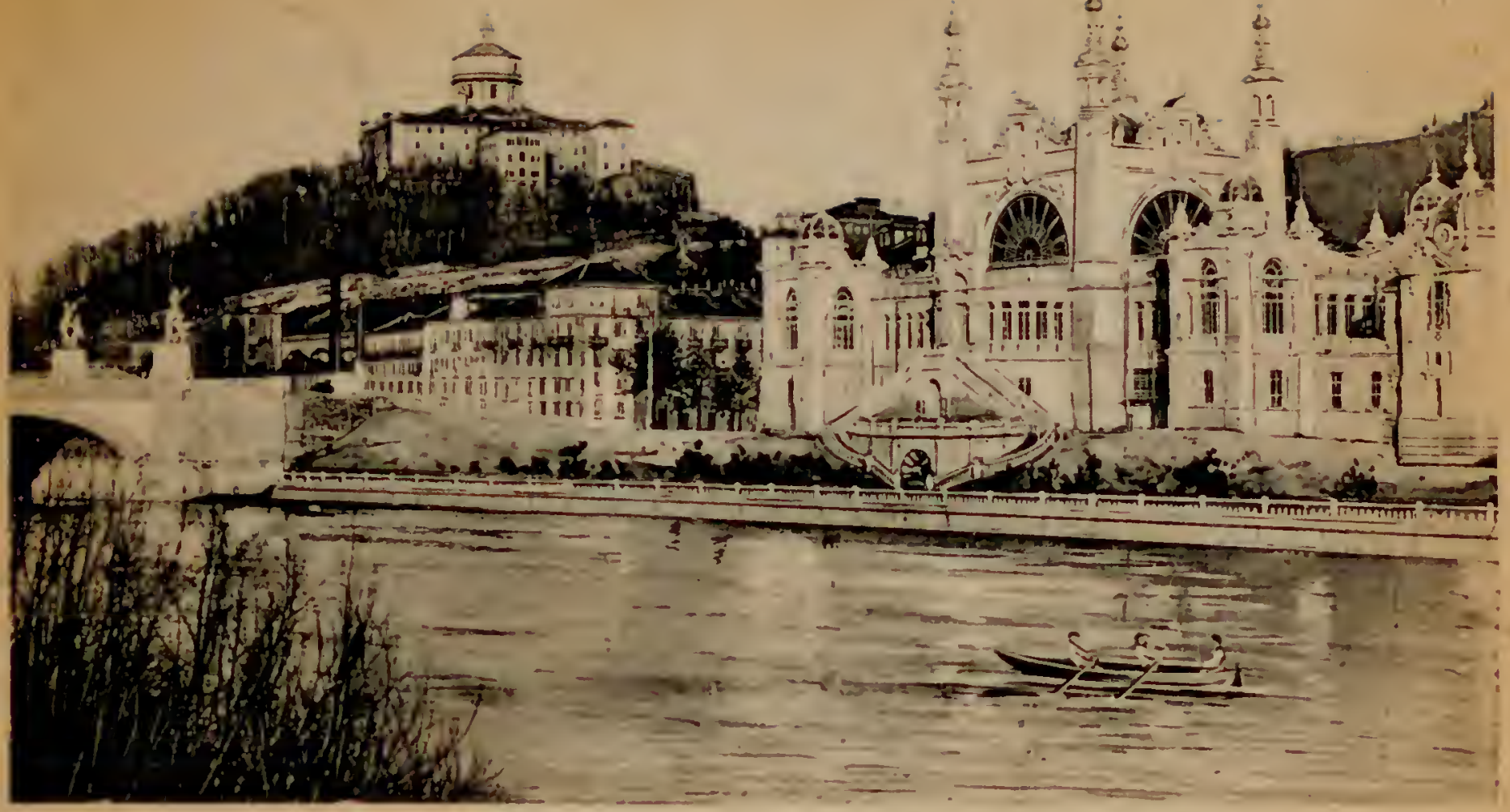

Padiglione dell' Argentina e vista del Monte dei Capuccini. 

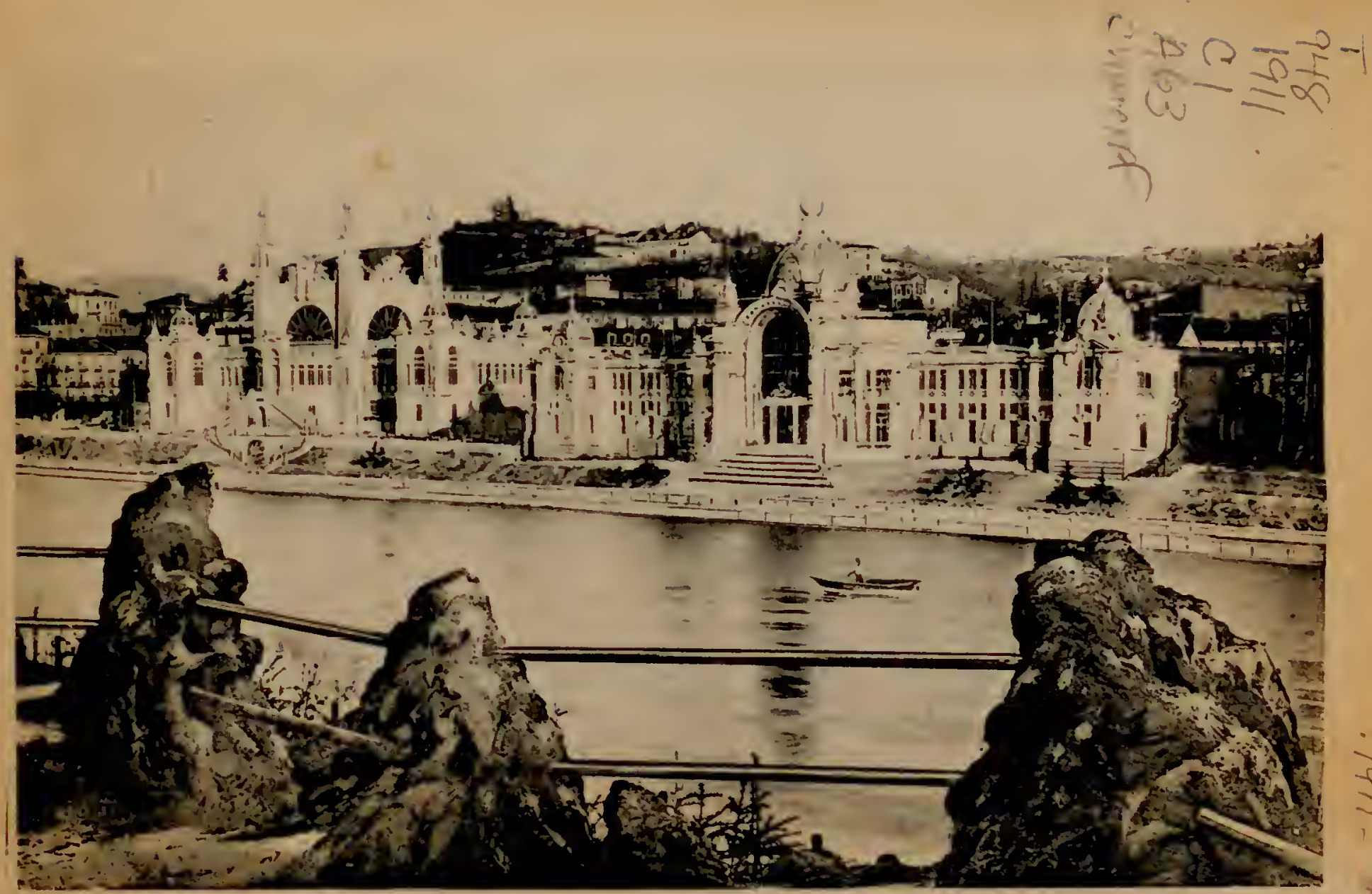

Padiglione Argentina ed America Latina. 


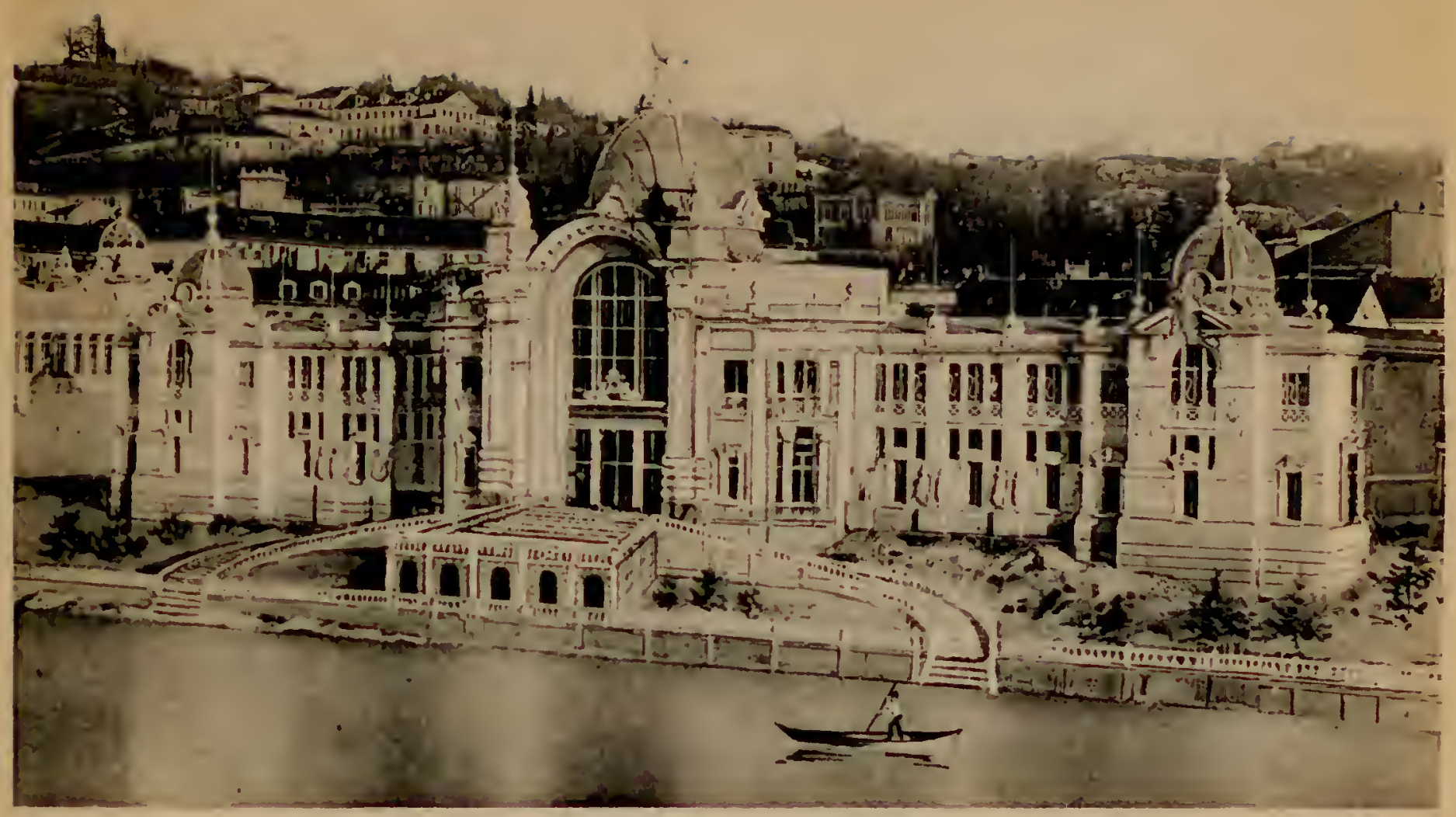

Padiglione America Latina. 


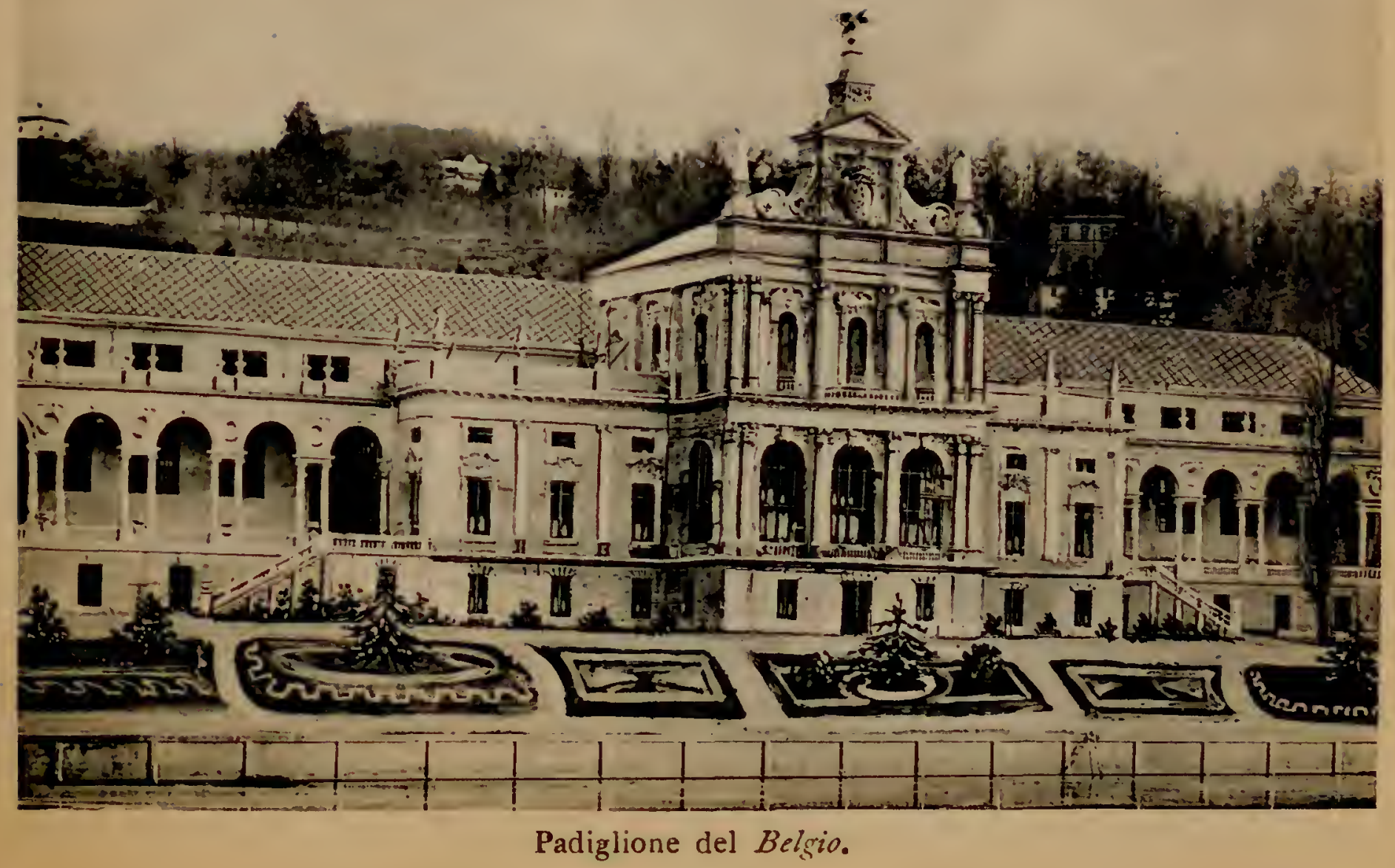




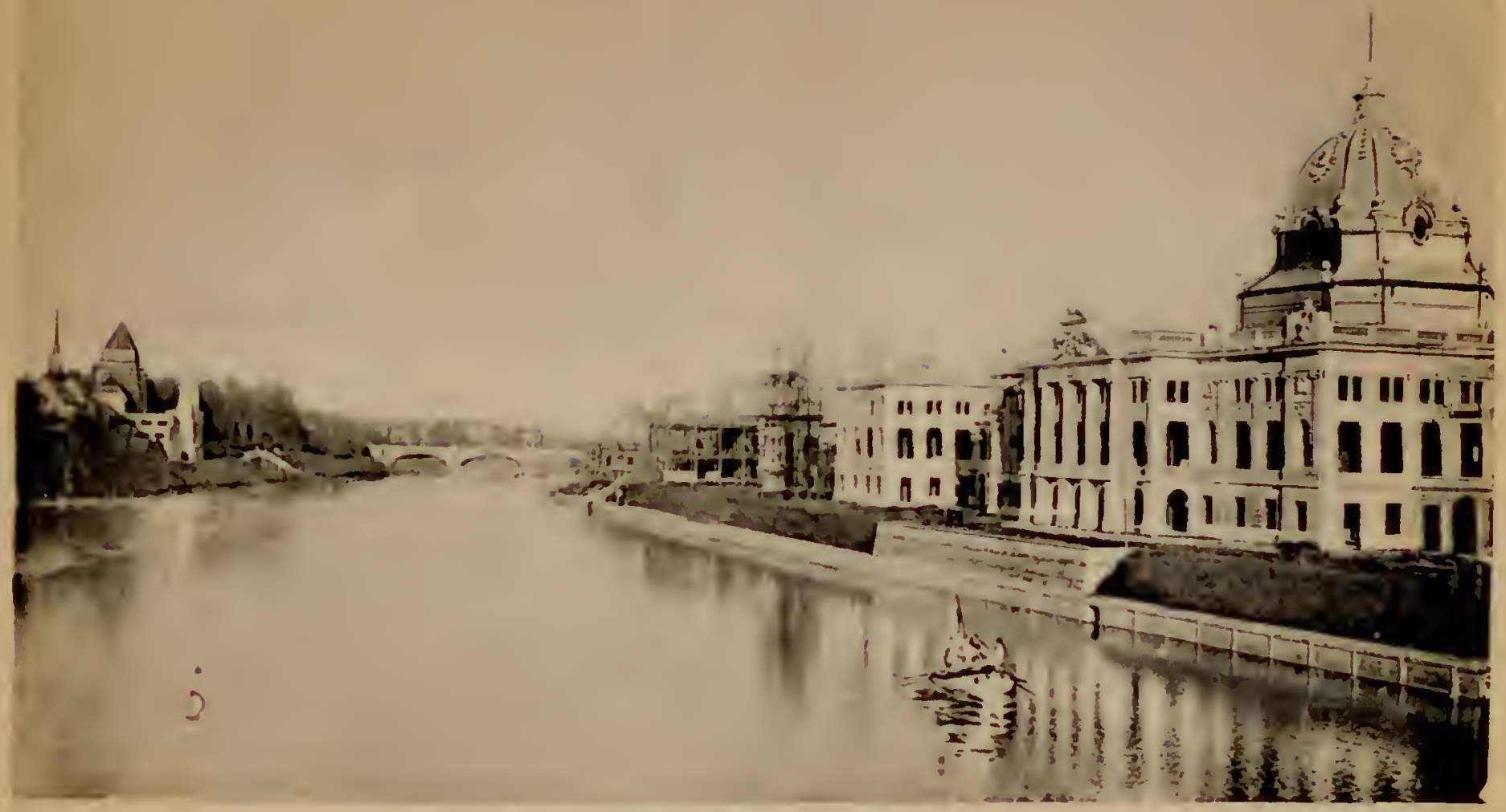

Grande vista sul $P_{0}$ 


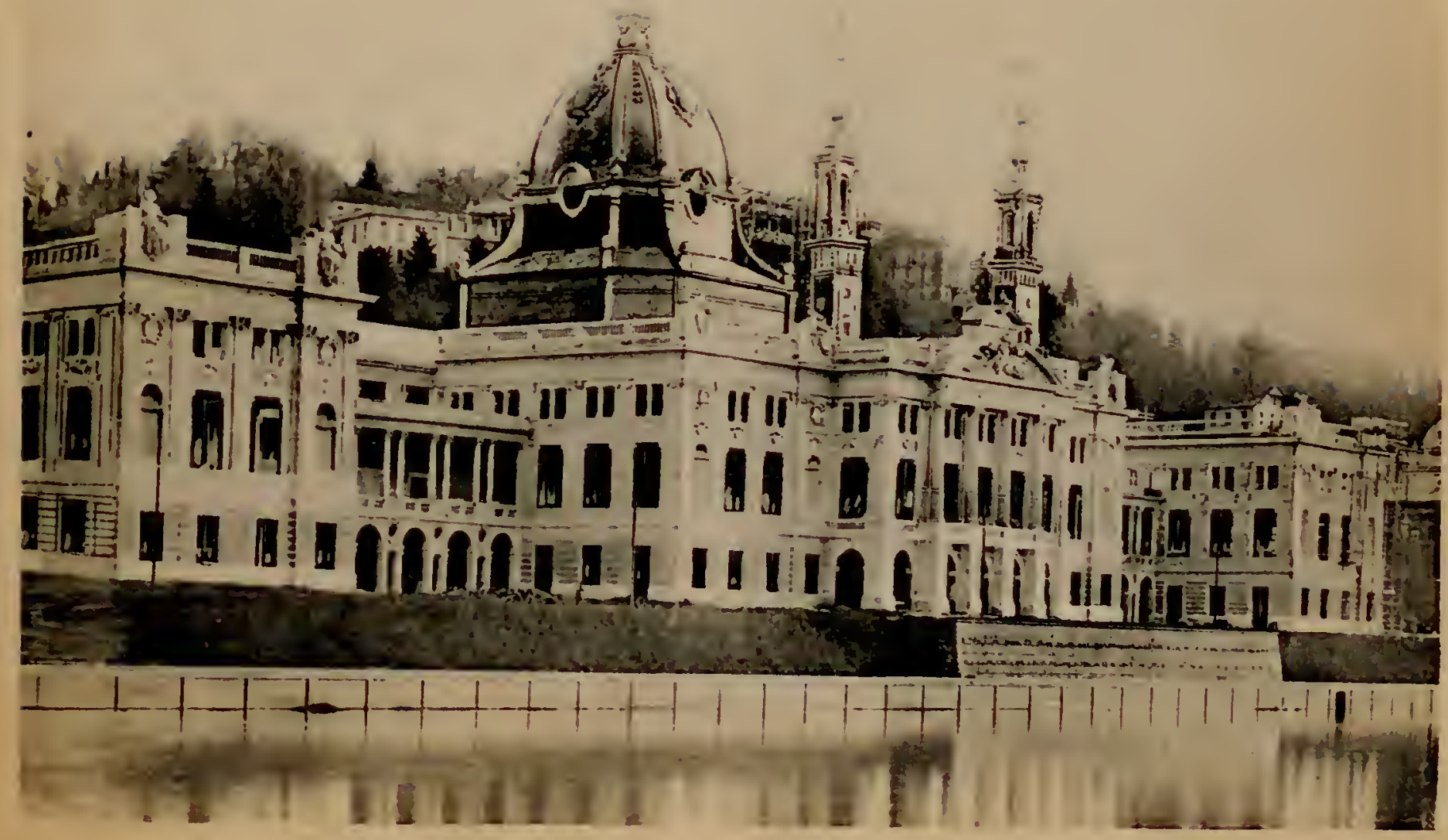

Padiglione della Franiia. 


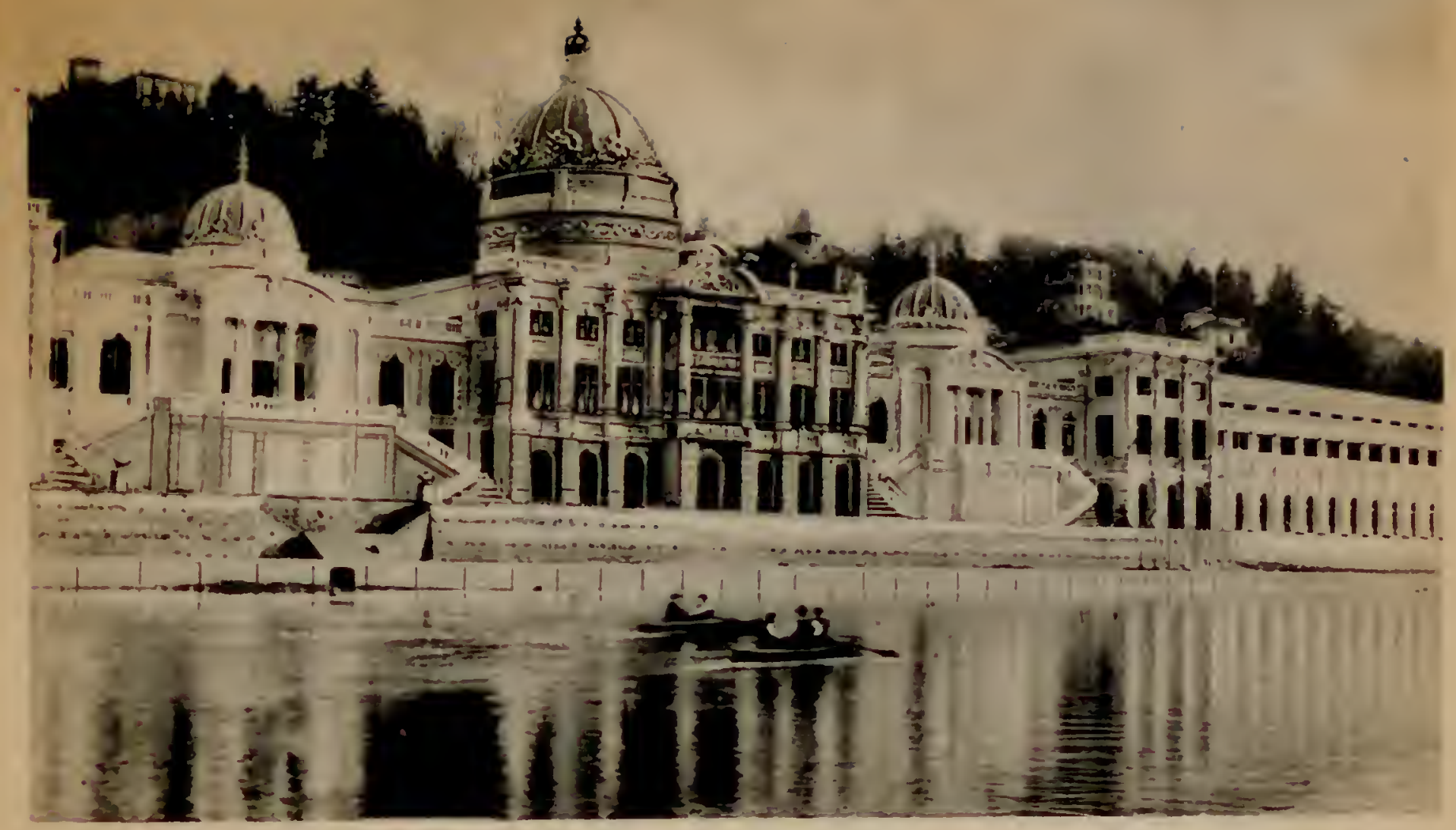

Padiglione della Germania 


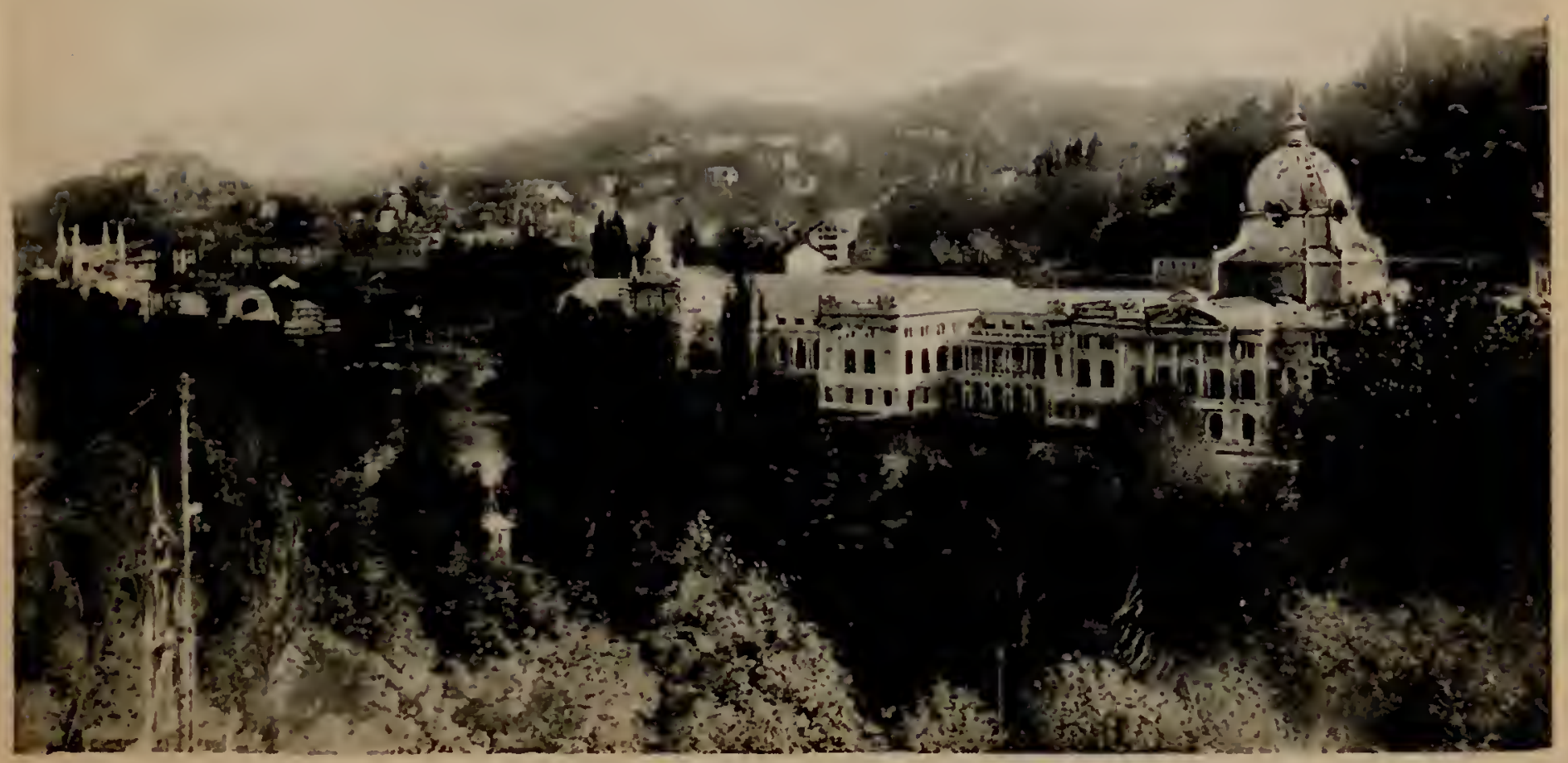

Panorama dal Restaurant du I'arc. 


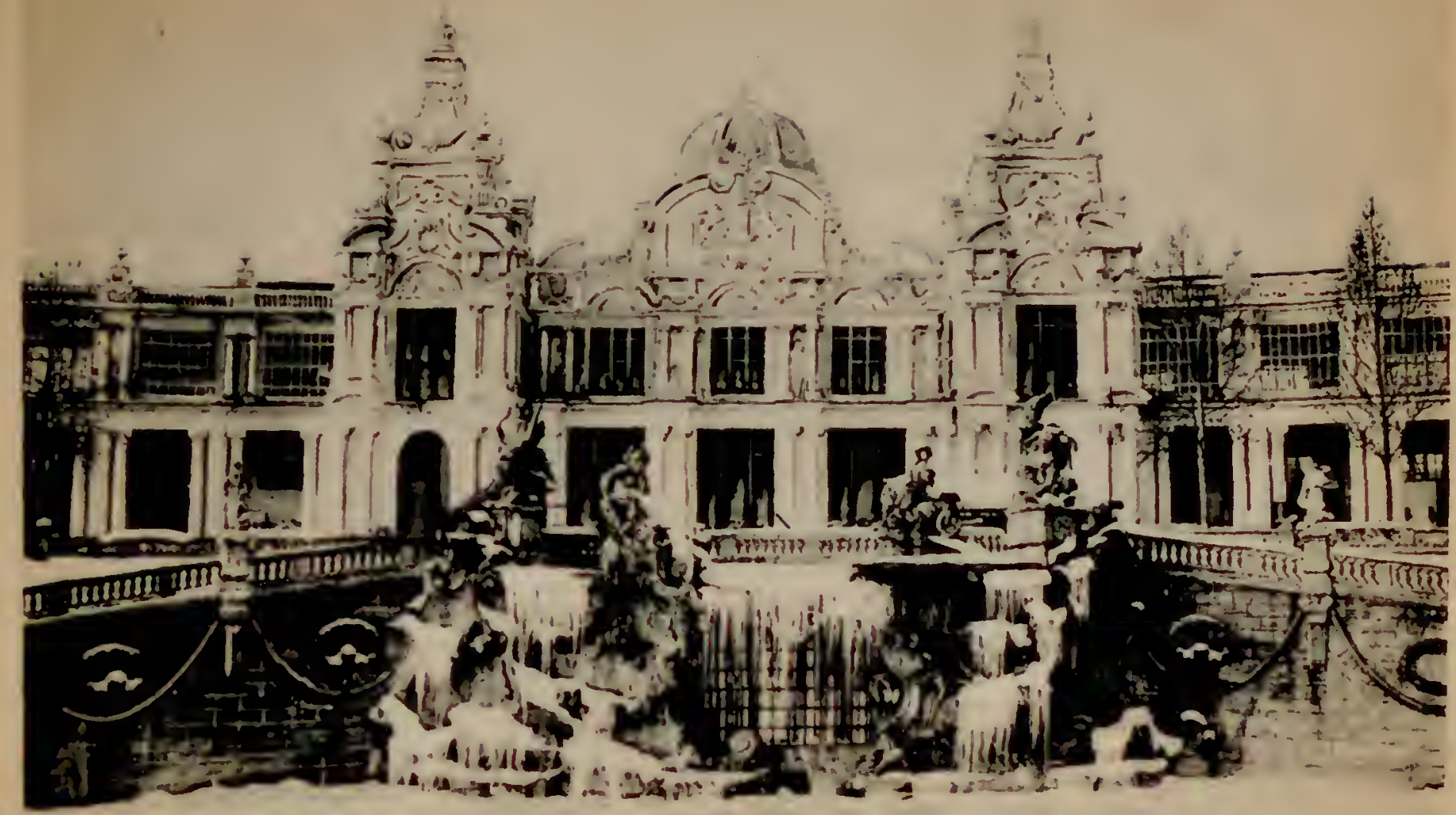

Padiglione Inglese 


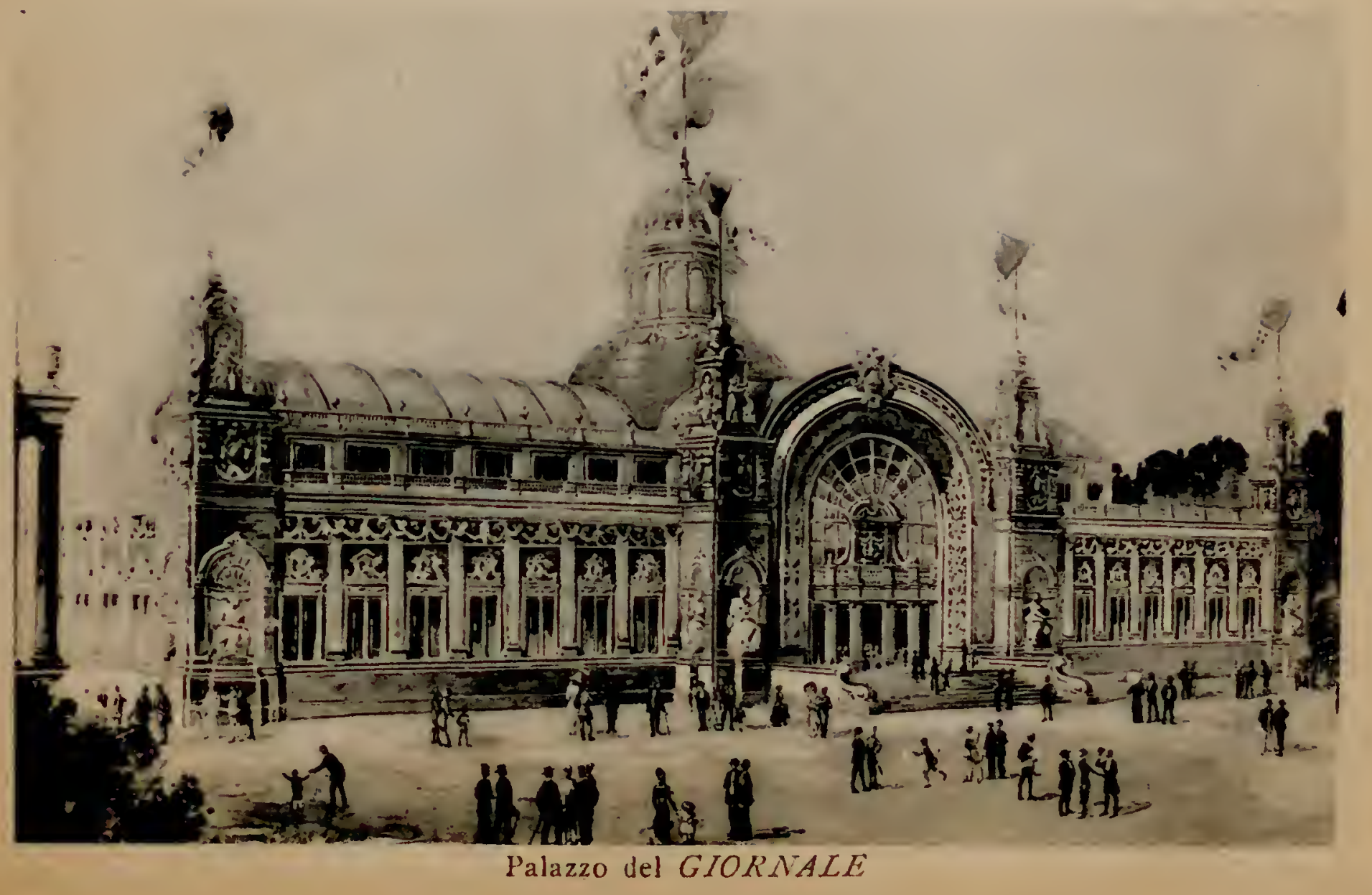




\section{- 3}

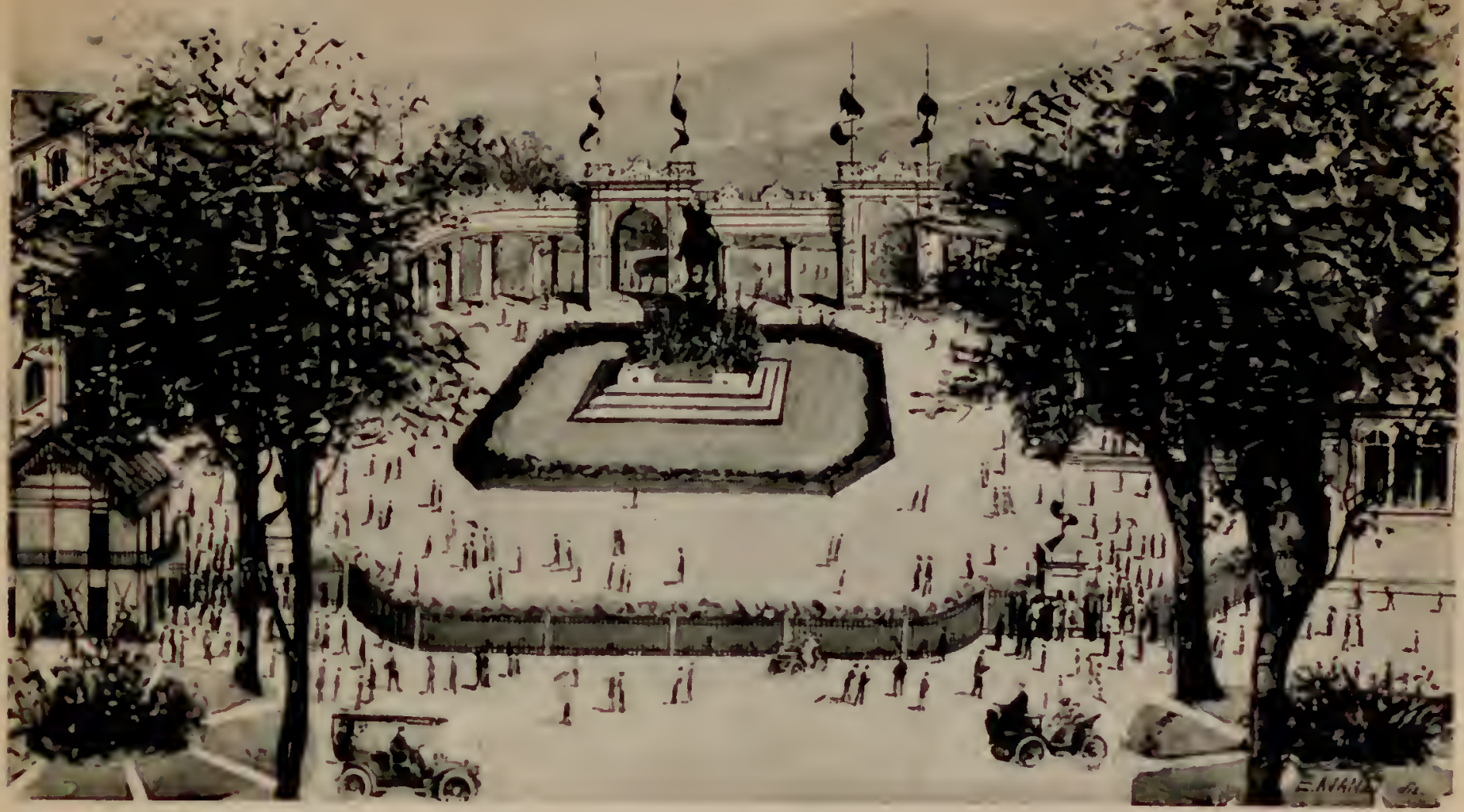

Ingresso dal Corso Raffaello 


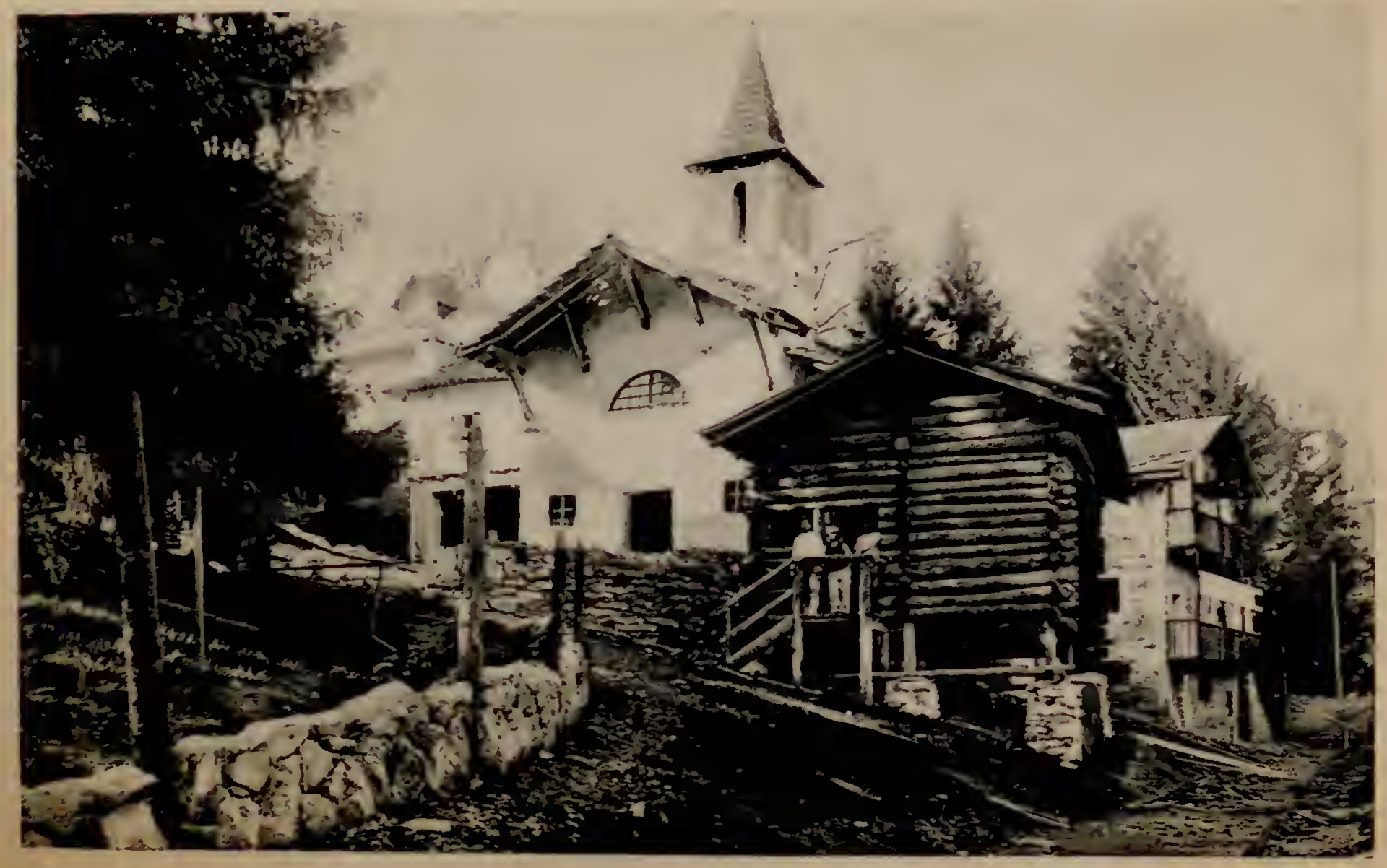

Villaggio Atpino 

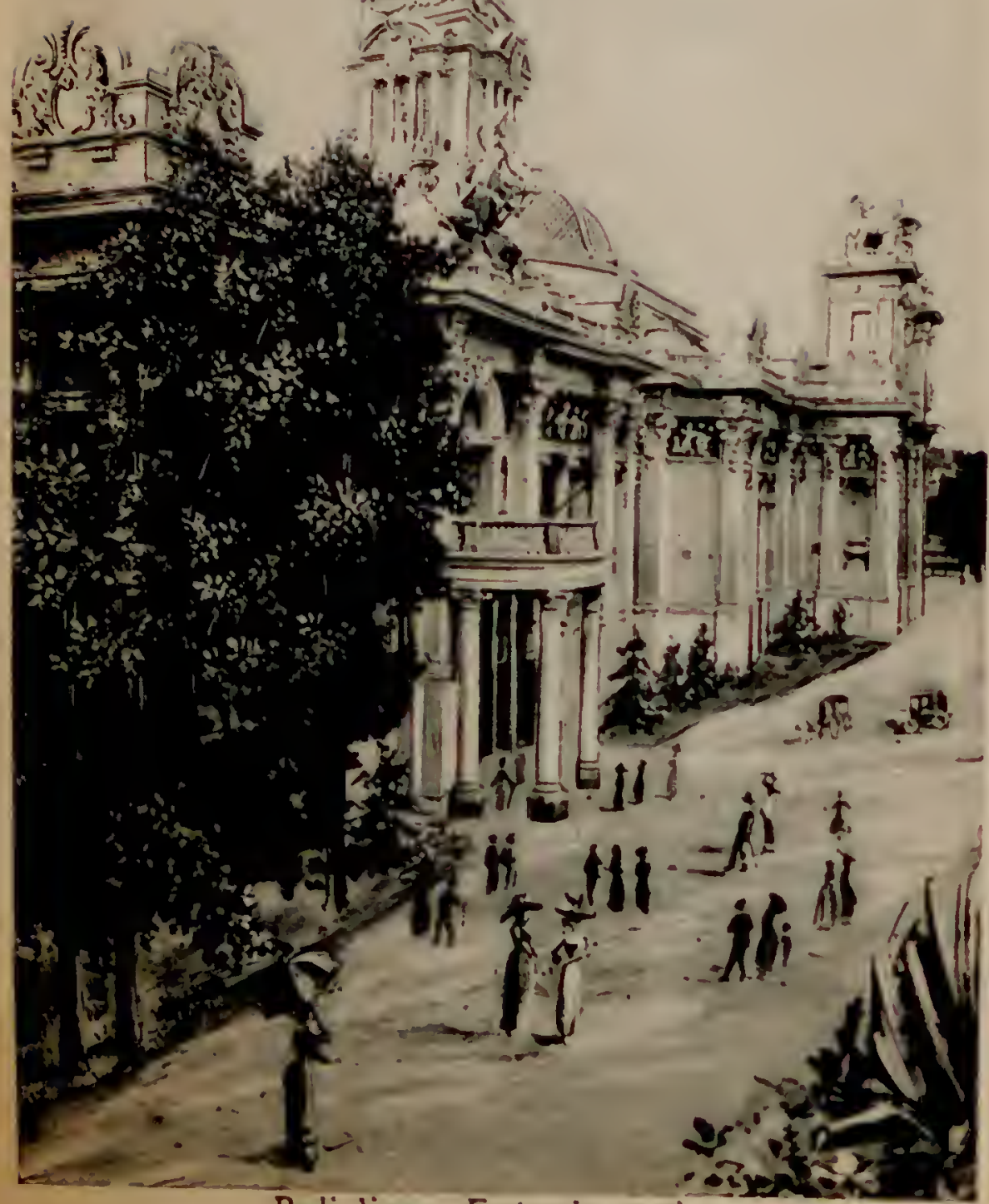

Padiglione Festeggiamenti 


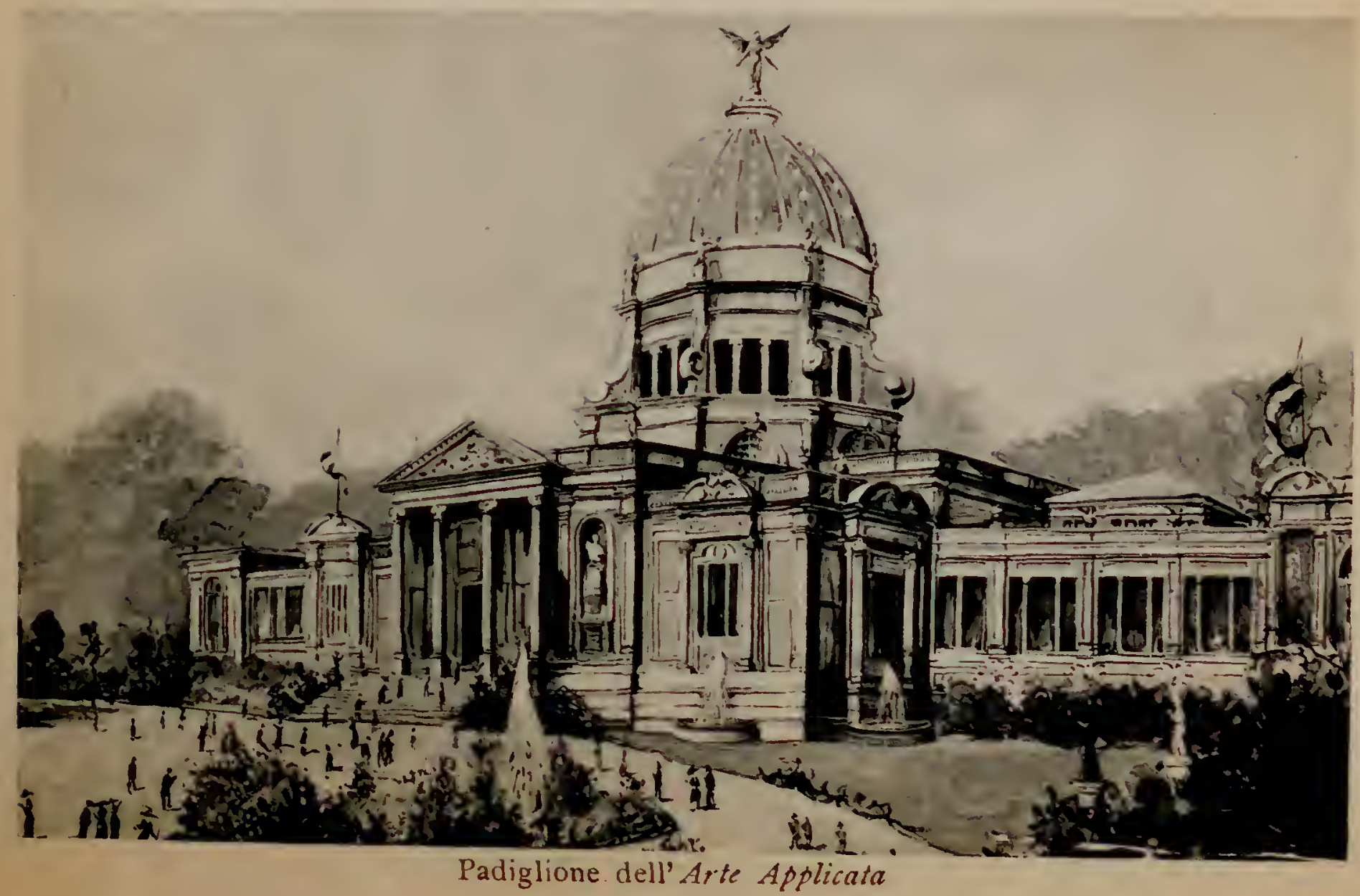




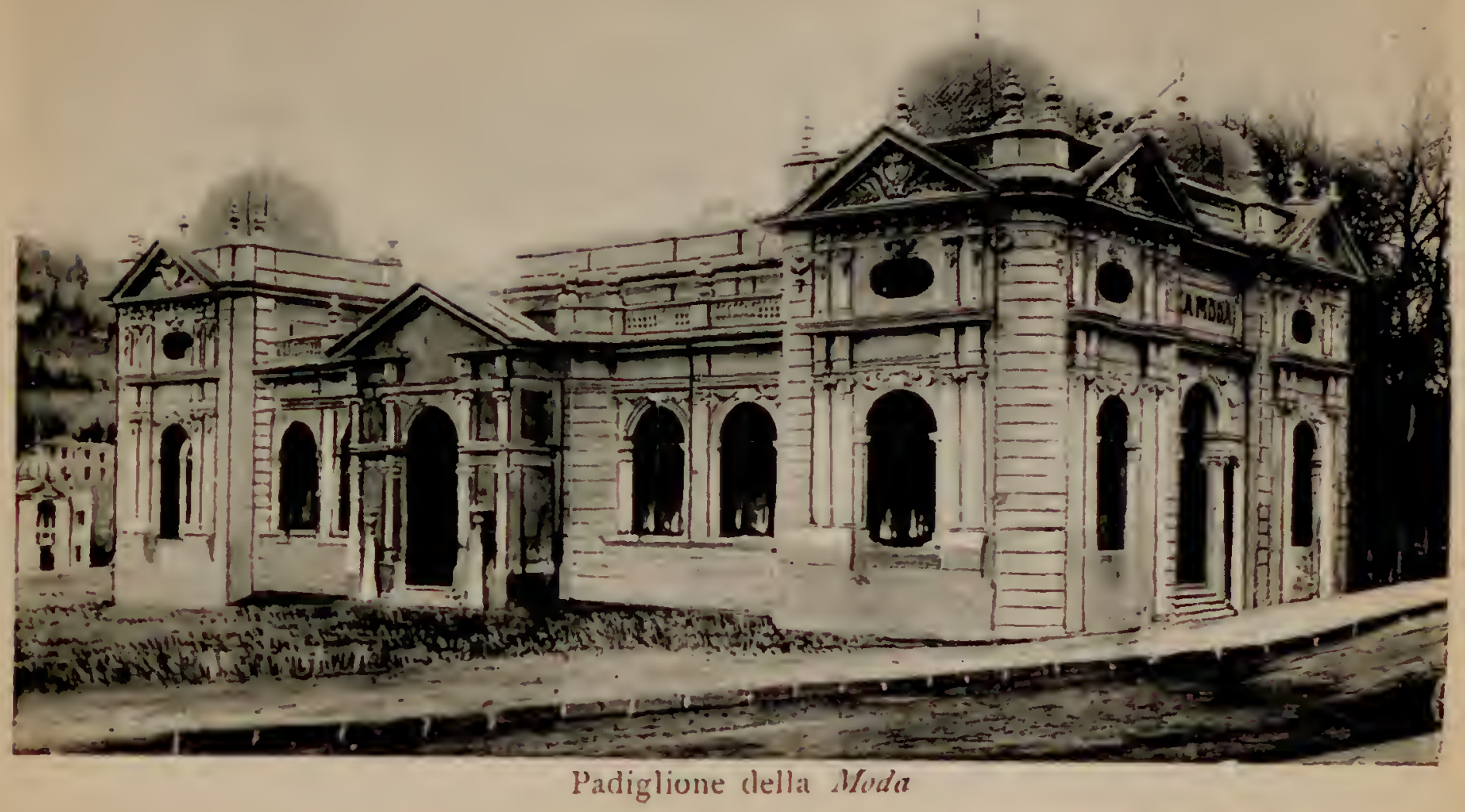




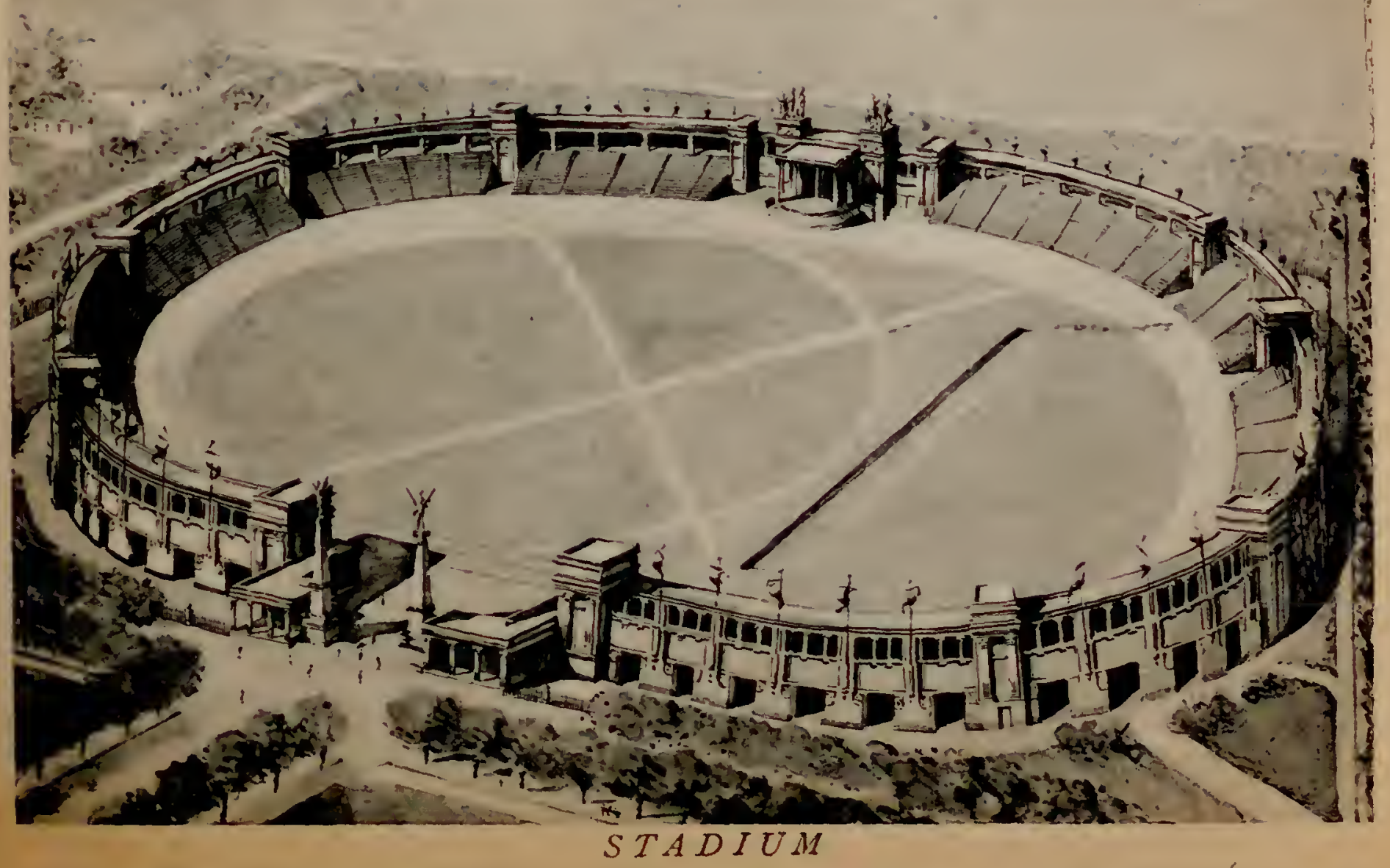






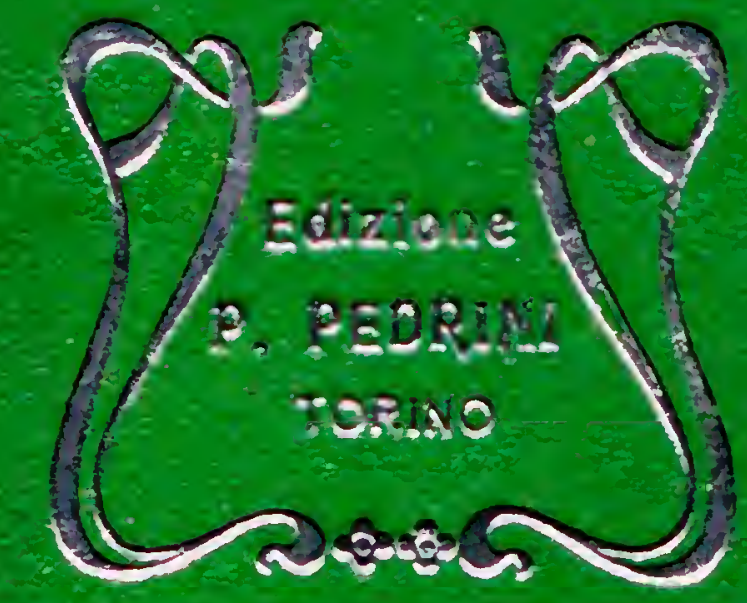

